\title{
Sustainable Fly Ash Based Roof Tiles with Waste Polythene Fibre: An Experimental Study
}

\author{
Mohammad N. Akhtar1 ${ }^{*}$, Jannisar Akhtar ${ }^{2}$, Omar H. Al Hattamleh${ }^{1}$, Abdulsamee M. Halahla ${ }^{1}$ \\ ${ }^{1}$ Department of Civil Engineering, Fahad Bin Sultan University, Tabuk, Kingdom of Saudi Arabia \\ ${ }^{2}$ Polytechnic Civil Engineering Section, Aligarh Muslim University, Aligarh, India \\ Email: ${ }^{n}$ nakhtar@fbsu.edu.sa
}

Received 29 January 2016; accepted 28 March 2016; published 31 March 2016

Copyright (C) 2016 by authors and Scientific Research Publishing Inc.

This work is licensed under the Creative Commons Attribution International License (CC BY).

http://creativecommons.org/licenses/by/4.0/

(c) (i) Open Access

\begin{abstract}
The compressive stress-strain behavior and other characteristics of treated fly ash based roof tiles have been studied by several experimental tests. This paper attempts to presents the results and observations of a study and comparison based on the past reported experimental data. Based on the results and observations of the comprehensive experimental study, five "control points" have been identified. The new sets of experiment have been carried out to investigate whether it might be possible the use of fly ash in fly ash based roof tiles for residential construction. In the present study, treated fly ash (TFA) of C category was used with different materials as a replacement of clay for making treated fly ash stone dust roof tiles (TFASDRT). Treated fly ash stone dust roof tiles (TFASDRT) were studied at varying percentages of cement, coarse sand, and radish stone dust (RSD) along with the constant percentage of waste polythene fibre (WPF). A research program was undertaken to evaluate the suitability of such test for assessing the properties of treated fly ash stone dust roof tiles (TFASDRT). The result of this study recommends that the fly ash based roof tiles provides a sustainable supplement to the traditional clay roof tiles, they increase the efficiency of traditional roof tiles and significantly help to reduce the environmental issues associated with the disposal of these waste materials.
\end{abstract}

\section{Keywords}

Fly Ash, Cement, Coarse Sand, Stone Dust, Waste Polythene Fibre, Compressive Strength

\footnotetext{
"Corresponding author.
}

How to cite this paper: Akhtar, M.N., Akhtar, J., Al Hattamleh, O.H. and Halahla, A.M. (2016) Sustainable Fly Ash Based Roof Tiles with Waste Polythene Fibre: An Experimental Study. Open Journal of Civil Engineering, 6, 314-327. 


\section{Introduction}

F.A particles typically solidify while they are still in suspension in exhaust gases and thus are generally spherical in shape. F.A is composed primarily of silica $\left(\mathrm{SiO}_{2}\right)$, alumina $\left(\mathrm{Al}_{2} \mathrm{O}_{3}\right)$, and iron oxide $\left(\mathrm{Fe}_{2} \mathrm{O}_{3}\right)$. Physical and chemical requirements for F.A usually vary depending on its intended use. Accordingly, specific requirements for use of F.A in concrete or soil stabilization are described in [1]. Standard specification for coal F.A and Raw or Calcined Natural Pozzolan for use in Concrete and [2], standard specification for F.A and other Pozzolans use with Lime for Soil stabilization, respectively. The plasticity index of mixture of fly ash and clay decreases on drastically with increase of replacing ratio of F.A was to be determined [3]. Against the destructive action of rain, the incorporation of F.A in pozzolanic plaster provides a satisfactory resistance to aggressive chemicals such as sulfate, salts and acids by [4]. Hydraulic conductivity or simply permeability (k) of freshly mixed cementitious-based materials is a key indicator of hydro mechanical properties (i.e., static stability, pumping, formwork pressure and plastic shrinkage) and their evolution with time. Several researchers reported that permeability of fresh concrete could be used to reflect its ability to remain homogeneous during the pumping and forming processes [5]. In the present study, F.A was used as a raw material to fully replace clay for making fly ash roof tiles. W.P.F is also an environmental issue as waste polythene fibres are difficult to biodegrade and involves processes either to recycle or reuse. Among different waste fractions, polythene waste deserves special attention on account non-biodegradable property which is a root cause for lots of environment problems. The aim of the present investigation is to find out a combination of materials, which gives a maximum compressive strength with F.A as a main constituent and cement, coarse sand, stone dust, lime, and waste polythene fibre as a supplementary constituent. The quantity of cement was kept up to $20 \%$ for economic consideration. The waste polythene bags cutting pieces have been tried as admixture to the F.A for improvement in its performance against seepage characteristics compressive strength and fracture.

\section{Experimental Program}

\subsection{Materials}

The F.A conforming [6], used in the study was the portion of the ash collected through electrostatics precipitators of Harduaganj Thermal Power Station Aligarh (U.P) India. The ordinary Portland cement of 43 Grade [7] was being used. The different types of waste polythene bags fibre were used in the experiment to carry daily usable items from general stores and shopping malls. The physical properties of different materials used in the study are given in Table 1 . The finely ground calcium hydroxide (laboratory regent) was being used to augment

Table 1. Material and their physical properties.

\begin{tabular}{|c|c|c|c|}
\hline Materials & Physical Properties & Value & Source \\
\hline C (OPC) 43 Grade & $\begin{array}{l}\text { Normal Consistency } \\
\text { Initial Setting Time } \\
\text { Final Setting Time } \\
\text { Compressive Strength } \\
\text { (1:3 Cement Sand Mortar) } \\
\text { Tensile Strength } \\
\text { (1:3 Cement Sand Mortar) }\end{array}$ & $\begin{array}{c}28 \% \\
33 \mathrm{~min} \\
389 \mathrm{~min} \\
\text { 19.3 MPa (3 Days) } \\
\text { 28.5 MPa (7 Days) } \\
\text { 1.9 Mpa (3 Days) } \\
\text { 2.45 Mpa (7 Days) }\end{array}$ & Locally Available \\
\hline T.F.A & $\begin{array}{l}\text { Specific Gravity } \\
\text { Optimum Moisture Content } \\
\text { Maximum Dry Density } \\
\text { Angle of Shear Resistance }\end{array}$ & $\begin{array}{c}1.92\left(25^{\circ} \mathrm{C}\right) \\
18.2 \%(\mathrm{SPT}) \\
1.28 \mathrm{gm} / \mathrm{cc} \\
29^{\circ}\end{array}$ & Harduaganj Thermal Power Station (India) \\
\hline C.D & $\begin{array}{l}\text { Specific Gravity } \\
\text { Water Absorption (30 min) } \\
\text { Fineness Modulus } \\
\text { Silt Content }\end{array}$ & $\begin{array}{c}2.66 \\
0.36 \% \\
2.8 \\
2.4 \%\end{array}$ & Locally Available \\
\hline R.S.D & $\begin{array}{l}\text { Specific Gravity } \\
\text { Water Absorption (30 min) } \\
\text { Fineness Modulus } \\
\text { Silt Content }\end{array}$ & $\begin{array}{c}2.67 \\
0.38 \% \\
2.72 \\
2.0 \%\end{array}$ & Locally Available \\
\hline W.P.F & $\begin{array}{l}\text { Length } \\
\text { Width }\end{array}$ & $\begin{array}{c}5 \mathrm{~mm} \\
25 \mathrm{~mm}\end{array}$ & Locally Available \\
\hline
\end{tabular}


the cementitious properties of the F.A. Its optimum amount with respect to optimum moisture contents (OMC) and maximum dry density (MDD) was determined through Standard Proctor's Test [8]. Several tests were carried out in order to evaluate the strength of treated fly ash based roof tiles.

\subsection{Chemical Analysis of T.F.A and R.S.D}

A scanning electron microscope (SEM) and energy dispersive X-ray microanalysis (EDS) techniques are being used in the chemical analysis of T.F.A and R.S.D. In the construction industry, the combination of SEM and EDS are being used particularly for quality control and verification of material composition. The VEGA3 SEM, which is fully compatible with any EDS system, is a powerful tool for quality control and development in the construction industry. Locally available T.F.A and R.S.D samples were examined in the present study. After examination of the samples it has been found that both samples were non-hazardous in nature and vigorously used as an additional construction materials. EDS analysis was performed using Bruker's Quantax system to determine the chemical composition of the T.F.A and R.S.D particles. The chemical composition of T.F.A and R.S.D particles and the element distribution over the sample surface was determined by EDS. Exact chemical composition is then summarized in Table 2 and Table 3.

Apart from oxygen, silicon and aluminum, from which the fly ash is usually composed; many other elements were found as well. In R.S.D sample iron and many other elements also found with the combination of oxygen, silicon and aluminum. The presence of diverse elements in fly ash particles might be attributed to the kind of coal being burned. The Quantitative results from point analysis of T.F.A and R.S.D are being used in the study are also shown in Figure 1 and Figure 2.

The fly ash consists of fine powdery particles that are predominantly spherical in shape, either solid or hollow and mostly glassy in nature. The particles size distribution of most bituminous coal fly ashes is generally similar to that of silt $(<0.075 \mathrm{~mm})$. Although, Sub-bituminous coal fly ashes or class $\mathrm{C}$ fly ash is generally slightly coarser than bituminous coal ranges between $0.002 \mathrm{~mm}-0.1 \mathrm{~mm}$. As can be seen in Figure 3, the variation of particles in Scanning Electron Microscope (SEM): T.F.A at 3000x Magnification and Figure 4 shows SE image of T.F.A at 6000x Magnification were collected from Harduaganj Thermal Power Station U.P (India).

Construction material such as Radish Stone Dust (R.S.D) admixtures are mixed with cement particles and improved the particle packing of cement paste, thus reducing permeability (k). Figure 5 and Figure 6 show the

Table 2. List of elements and concentrations of T.F.A.

\begin{tabular}{ccc}
\hline Element & Weight \% & Atomic \% \\
\hline $\mathrm{C}$ & 14.42 & 21.05 \\
$\mathrm{O}$ & 54.59 & 59.83 \\
$\mathrm{Al}$ & 11.96 & 7.77 \\
$\mathrm{Si}$ & 16.47 & 10.29 \\
$\mathrm{~K}$ & 0.73 & 0.33 \\
$\mathrm{Ca}$ & 0.94 & 0.41 \\
$\mathrm{Ti}$ & 0.88 & 0.32 \\
Totals & 100.00 & \\
\hline
\end{tabular}

\begin{tabular}{|c|c|c|}
\hline Element & Weight \% & Atomic \% \\
\hline $\mathrm{O}$ & 59.96 & 75.21 \\
\hline $\mathrm{Al}$ & 11.11 & 8.26 \\
\hline $\mathrm{Si}$ & 19.53 & 13.95 \\
\hline K & 2.17 & 1.11 \\
\hline $\mathrm{Fe}$ & 2.81 & 1.01 \\
\hline $\mathrm{Au}$ & 4.42 & 0.45 \\
\hline Totals & 100.00 & \\
\hline
\end{tabular}




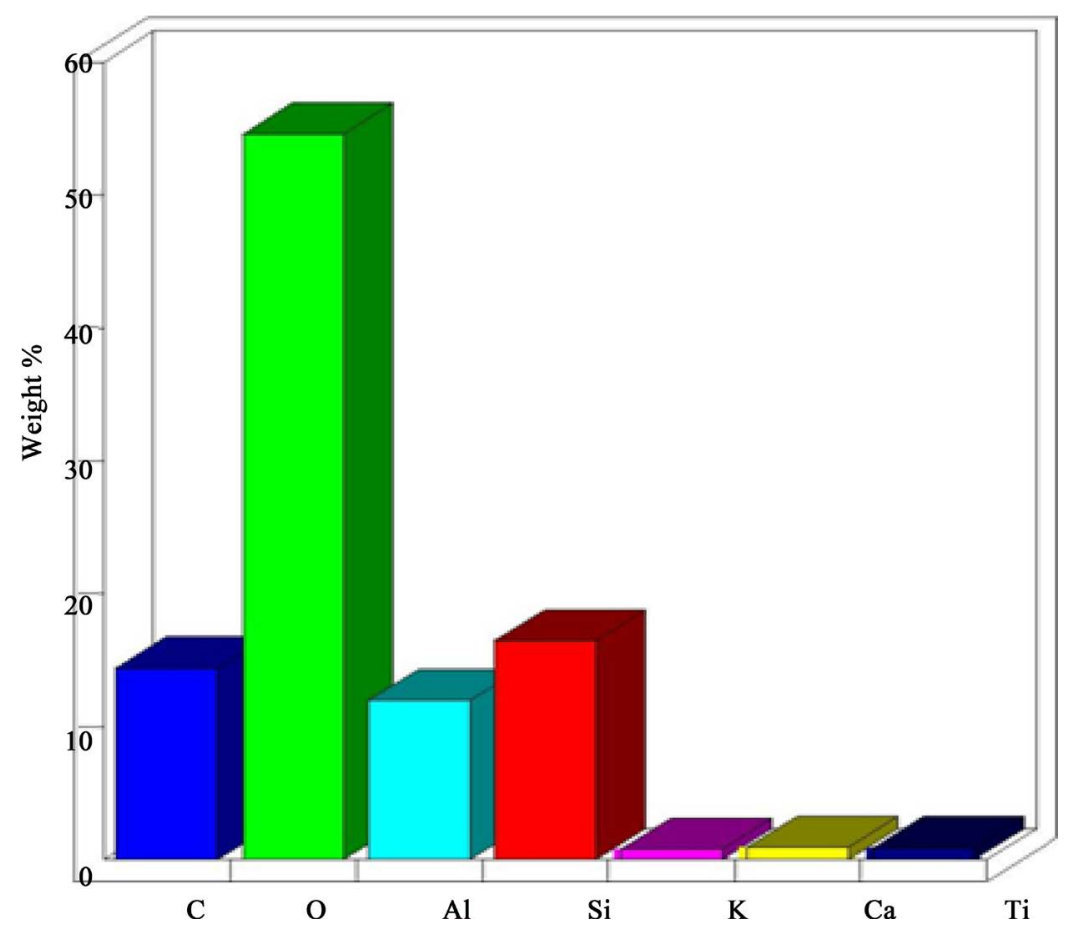

Figure 1. Quantitative results from point analysis of TFA.

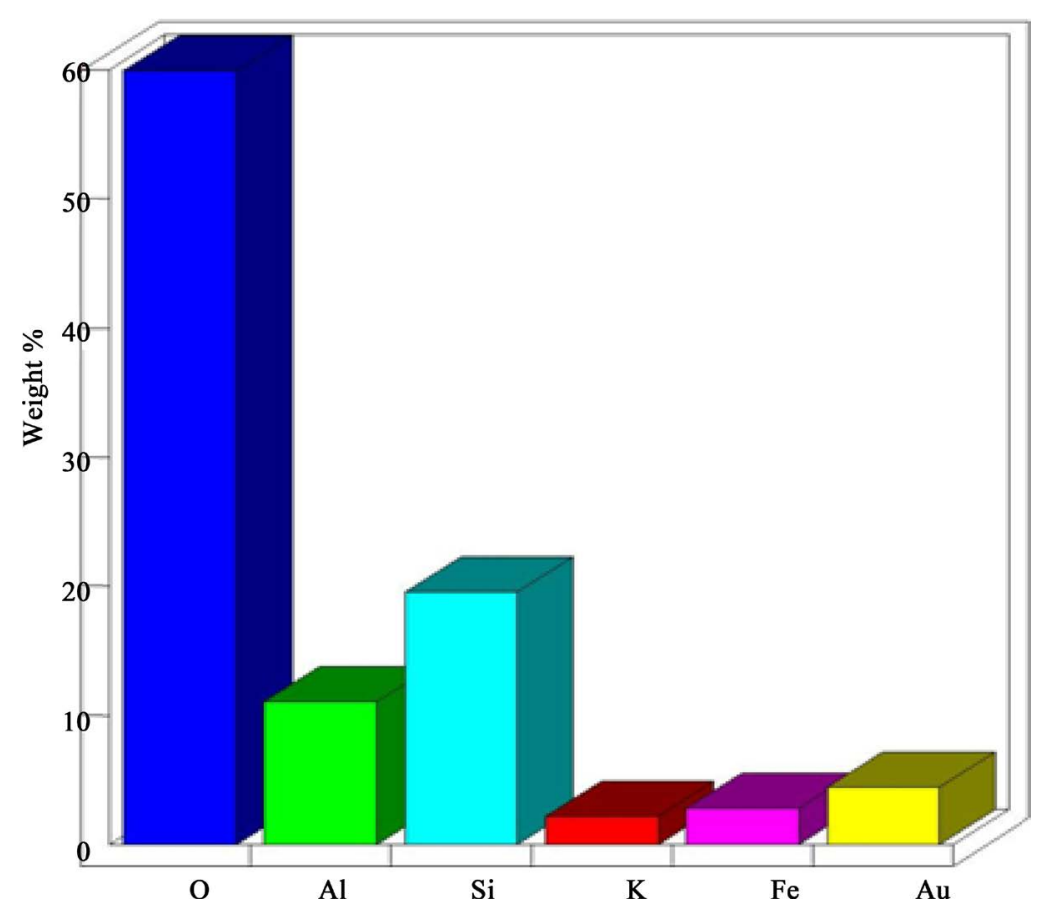

Figure 2. Quantitative results from point analysis of RSD.

Scanning Electron Microscope (SEM): R.S.D particles at 3000x magnification and SE image of R.S.D at 6000× magnification was collected locally used in the present study.

\subsection{Benefits of Fly Ash Based Composite Material with Cement}

Cement is a binding material, which is widely used in the construction industry. It is made from limestone, clay 
and various additives, such as powered gypsum and fly ash. Gypsum $\left(\mathrm{CaSO}_{4} \cdot 2 \mathrm{H}_{2} \mathrm{O}\right)$ is a common and soft mineral. It is used as a set retarder in the early stage of hydration. It keeps the mortar of the concrete in a plastic stage for longer time and therefore it prolongs concrete workability. The combination of T.F.A and R.S.D with cement discloses the various important benefits of the composite material. The replacement of cement by fly ash reduces the water demand and the decreased water demand has a little or no effect on drying shrinkage/cracking. So, the reduction in free lime and the resulting increase in cementitious compounds combined with the reduction in permeability and enhance the mortar durability. The additional binder produced by the fly ash reaction with available lime allows fly ash based composite material to continue to gain strength over time.

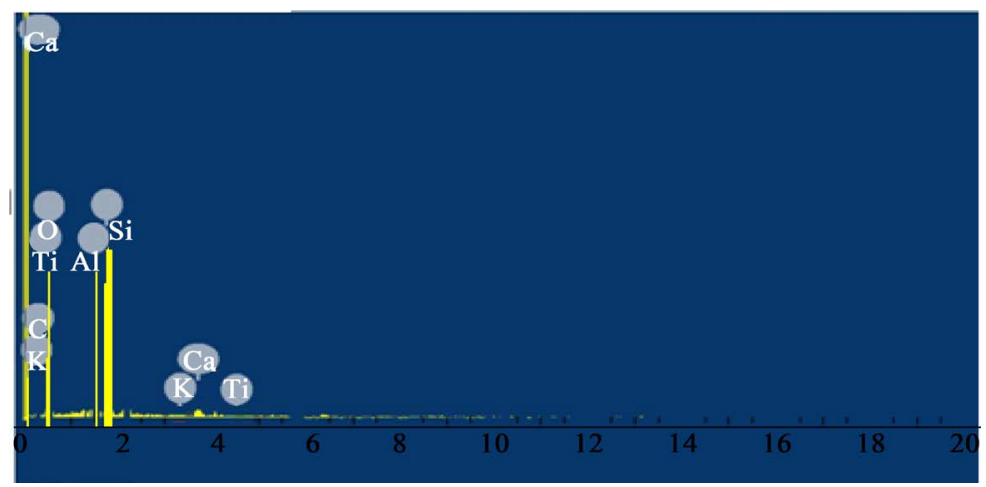

Figure 3. Spectrum from point analysis of TFA particles at 3000×.

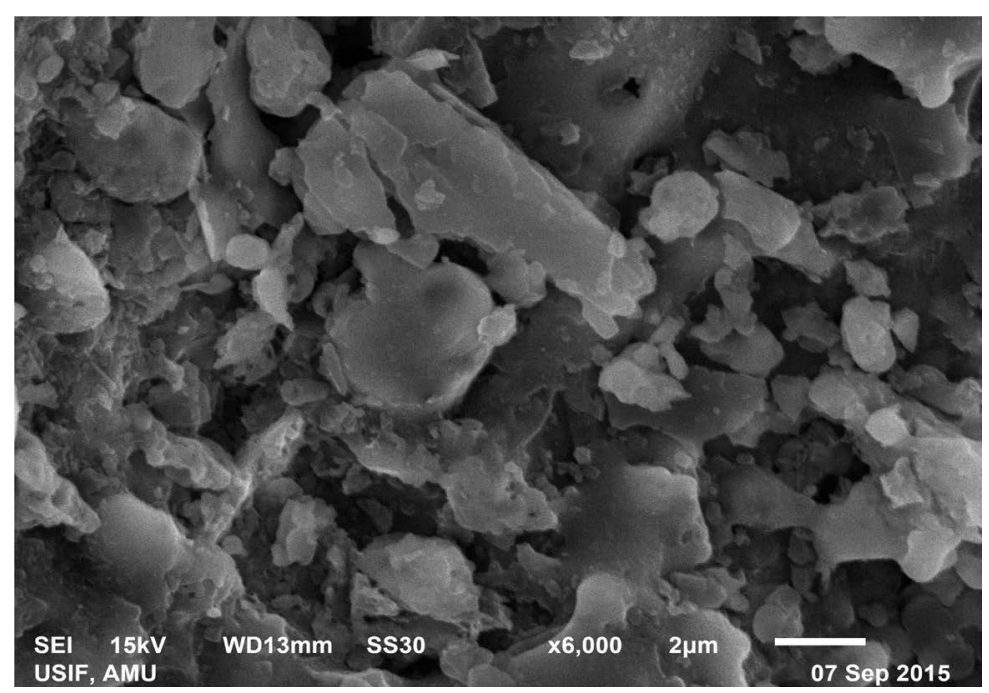

Figure 4. SE image of TFA at $6000 \times$.

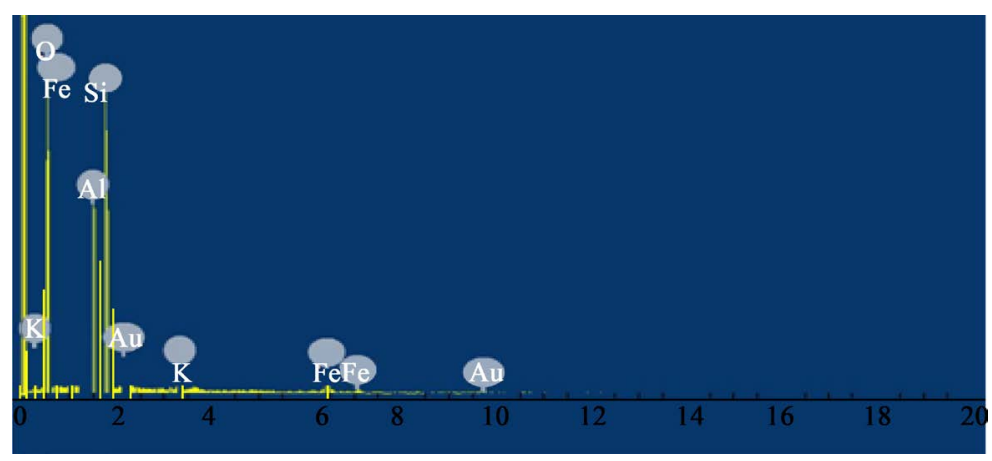

Figure 5. Spectrum from point analysis of RSD particles at 3000×. 


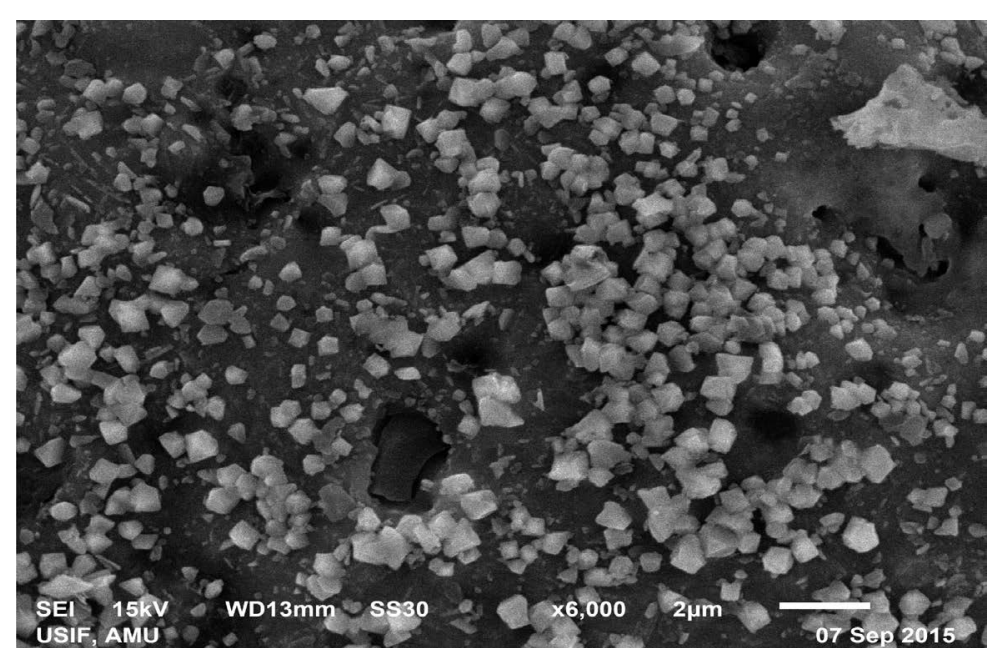

Figure 6. SE image of RSD 6000×.

\subsection{Strength Testing of Clay Based Tiles}

In order to evaluate the strength of clay based tiles available in the market several tests were carried out. Local brick tiles from four different manufacturers (designated as $\mathrm{M}, \mathrm{B}, \mathrm{S}$ and $\mathrm{O}$ ) were used having approximate length as 230, 110 and $38 \mathrm{~mm}$ respectively. The summaries of test results are shown in Table 4. An average compressive strength for all the clay brick tiles used in the study is shown in the Figure 7(a). The water absorption capacity of the tile material is given by the WA test. The absorption of moisture by capillary action in the tiles produces a suction effect that draws water from mortar and this characteristic is defined by IRA. The rate of absorption can have an important effect on the interaction between freshly laid mortar and the brick and tile units. IRA was measured in order to assist in mortar selection and material handling in the construction process. It was measured in terms of mass of water absorbed per minute by the brick material per unit area of brick immersed in about $3 \mathrm{~mm}$ deep water, which was kept constant by adding water during the test, as per [9] [10], was used to perform a WA test whose provisions are similar to those given in [9].

\subsection{Batching of Mixtures}

The mixing procedure for the mortars consists of homogeneous materials with measured quantity of water mixing, and then introducing the cementitious materials gradually over 30 seconds. After a break period of 30 seconds, the composite material was remixed for another 2 min. As summarized in Table 5, six composite series were made with the variation of C, T.F.A C.S and S.D. Three moulds of each combination were prepared for strength determination of roof tiles. The weighted material was placed on a level platform, W.P.F sprinkled gently on it and was mixed using mixer. Care was taken to prevent agglomeration of fibres and to ensure their uniform distribution as far as possible. The fresh mortar was poured into three equal layers in the mould also properly placed and compact. In each series, different combinations of, C, T.F.A, C.S and S.D were tested at the same combination of W.P.F. Testing and sampling of all composite mixtures was made at room temperature $\left(25^{\circ} \mathrm{C} \pm 2^{\circ} \mathrm{C}\right)$.

\subsection{Strength Testing of Fly Ash Based Tiles}

To avoid entrapment of air, the tested material was well compacted using a tamping device in three layers of approximate similar heights, several tests were carried out in order to evaluate the compressive strength and stress-strain characteristics of fly ash based roof tiles. The six different combination of TFASDRT were tested as summarized in Table 5, having approximate length, width and height as 230, 110, and $38 \mathrm{~mm}$, respectively. The tests were performed in accordance with [10].

Phase 1: validity of compressive behavior of fly ash tiles

The perusal of three combinations in phase 1 at $70 \%, 60 \%$ and $50 \%$ of fly ash gives the maximum value at $50 \%$ fly ash combination. Using this approach to set the maximum percentage of T.F.A was $50 \%$ for phase 2 obser- 
Table 4. Summary of test result for clay tiles.

\begin{tabular}{cccc}
\hline Material & Compressive Strength (MPa) & Water Absorption (\%) & Source \\
\hline M (10 Specimen) & 9.10 & 11.95 & Locally \\
B (10 Specimen) & 9.05 & 11.38 & Locally \\
O (10 Specimen) & 9.30 & 11.13 & Locally \\
S (10 Specimen) & 9.40 & 12.25 & Locally \\
Average (40 Specimens) & & & \\
\hline
\end{tabular}

Table 5. Summary of test results for fly ash based tiles.

\begin{tabular}{|c|c|c|c|c|c|c|c|c|}
\hline \multirow{2}{*}{$\begin{array}{c}\text { Mould } \\
\text { Designation }\end{array}$} & \multicolumn{4}{|c|}{ Mix Proportions } & \multirow{2}{*}{ W.P.F (\%) } & \multirow{2}{*}{$\begin{array}{l}\text { Compressive } \\
\text { Strength (MPa) }\end{array}$} & \multirow{2}{*}{$\begin{array}{c}\mathrm{K}_{27}(\mathrm{~m} / \mathrm{s}) \\
\text { M.N Akhtar et al. } \\
(2014)\end{array}$} & \multirow{2}{*}{ Ratios of Sample } \\
\hline & C (\%) & T.F.A (\%) & C.S (\%) & S.D (\%) & & & & \\
\hline \multicolumn{9}{|l|}{ Phase 1} \\
\hline 00 TFASDRT & 10 & 70 & 20 & 00 & 1 & 3.56 & $4.603 \times 10^{-7}$ & $1: 7: 2: 0$ \\
\hline 05 TFASDRT & 10 & 70 & 15 & 05 & 1 & 3.84 & $4.310 \times 10^{-7}$ & $1: 7: 1.5: 0.5$ \\
\hline 10 TFASDRT & 10 & 70 & 10 & 10 & 1 & 4.25 & $3.911 \times 10^{-7}$ & 1:7:1:1 \\
\hline 15 TFASDRT & 10 & 70 & 05 & 15 & 1 & 4.19 & $3.618 \times 10^{-7}$ & $1: 7: 0.5: 1.5$ \\
\hline 20 TFASDRT & 10 & 70 & 00 & 20 & 1 & 3.89 & $3.240 \times 10^{-7}$ & $1: 7: 0: 2$ \\
\hline 00 TFASDRT & 10 & 60 & 30 & 00 & 1 & 3.74 & $2.937 \times 10^{-7}$ & 1:6:3:0 \\
\hline 05 TFASDRT & 10 & 60 & 25 & 05 & 1 & 4.06 & $2.815 \times 10^{-7}$ & $1: 6: 2.5: 0.5$ \\
\hline 10 TFASDRT & 10 & 60 & 20 & 10 & 1 & 4.47 & $2.525 \times 10^{-7}$ & $1: 6: 2: 1$ \\
\hline 15 TFASDRT & 10 & 60 & 15 & 15 & 1 & 4.35 & $2.330 \times 10^{-7}$ & 1:6:1.5:1.5 \\
\hline 20 TFASDRT & 10 & 60 & 10 & 20 & 1 & 4.15 & $2.180 \times 10^{-7}$ & $1: 6: 1: 2$ \\
\hline 00 TFASDRT & 10 & 50 & 40 & 00 & 1 & 4.05 & $4.777 \times 10^{-7}$ & $1: 5: 4: 0$ \\
\hline 05 TFASDRT & 10 & 50 & 35 & 05 & 1 & 4.35 & $4.462 \times 10^{-7}$ & 1:5:3.5:0.5 \\
\hline 10 TFASDRT & 10 & 50 & 30 & 10 & 1 & 4.61 & $4.238 \times 10^{-7}$ & 1:5:3:1 \\
\hline 15 TFASDRT & 10 & 50 & 25 & 15 & 1 & 4.53 & $4.068 \times 10^{-7}$ & $1: 5: 2.5: 1.5$ \\
\hline 20 TFASDRT & 10 & 50 & 20 & 20 & 1 & 4.41 & $4.020 \times 10^{-7}$ & 1:5:2:2 \\
\hline \multicolumn{9}{|l|}{ Phase 2} \\
\hline 10 TFASDRT & 10 & 50 & 30 & 10 & 1 & 4.61 & $1.941 \times 10^{-7}$ & 1:5:3:1 \\
\hline 15 TFASDRT & 10 & 50 & 25 & 15 & 1 & 4.53 & $1.844 \times 10^{-7}$ & $1: 5: 2.5: 1.5$ \\
\hline 20 TFASDRT & 10 & 50 & 20 & 20 & 1 & 4.41 & $1.691 \times 10^{-7}$ & $1: 5: 2: 2$ \\
\hline 25 TFASDRT & 10 & 50 & 15 & 25 & 1 & 4.38 & $1.650 \times 10^{-7}$ & 1:5:1.5:2.5 \\
\hline 30 TFASDRT & 10 & 50 & 10 & 30 & 1 & 4.25 & $1.555 \times 10^{-7}$ & 1:5:1:3 \\
\hline 10 TFASDRT & 15 & 50 & 25 & 10 & 1 & 6.04 & $1.244 \times 10^{-7}$ & 1:3.33:1.66:0.66 \\
\hline 15 TFASDRT & 15 & 50 & 20 & 15 & 1 & 6.54 & $1.169 \times 10^{-7}$ & 1:3.33:1.33:1 \\
\hline 20 TFASDRT & 15 & 50 & 15 & 20 & 1 & 6.98 & $1.147 \times 10^{-7}$ & 1:3.33:1:1.33 \\
\hline 25 TFASDRT & 15 & 50 & 10 & 25 & 1 & 6.35 & $1.088 \times 10^{-7}$ & 1:3.33:0.66:1.66 \\
\hline 30 TFASDRT & 15 & 50 & 05 & 30 & 1 & 6.30 & $1.032 \times 10^{-7}$ & 1:3.33:0.33:2 \\
\hline 10 TFASDRT & 20 & 50 & 20 & 10 & 1 & 8.52 & $1.134 \times 10^{-7}$ & $1: 2.5: 1: 0.5$ \\
\hline 15 TFASDRT & 20 & 50 & 15 & 15 & 1 & 8.75 & $1.025 \times 10^{-7}$ & $1: 2.5: 0.75: 0.75$ \\
\hline 20 TFASDRT & 20 & 50 & 10 & 20 & 1 & 9.01 & $0.953 \times 10^{-7}$ & 1:2.5:0.5:1 \\
\hline 25 TFASDRT & 20 & 50 & 05 & 25 & 1 & 8.95 & $0.914 \times 10^{-7}$ & $1: 2.5: 0: 25: 1.25$ \\
\hline 30 TFASDRT & 20 & 50 & 00 & 30 & 1 & 7.99 & $0.874 \times 10^{-7}$ & $1: 2.5: 0: 1.5$ \\
\hline
\end{tabular}

vation. The control point of this phase is that, there is no variation in cement and stone dust combination. On the other hand the significant changes were found in the strength with the variation of fly ash and coarse sand. The Figure 7(b) shows the variation in compressive strength for phase 1 observation.

\section{Phase 2: validity of compressive behavior of fly ash tiles}

The perusal of three combinations in phase 2 at $10 \%, 15 \%$ and $20 \%$ of cement with $50 \%$ fly ash combination fixed in phase 1 gives the maximum value at $20 \%$ cement combination. The control point of this phase is that, there is no variation in treated fly ash and stone dust combination. On the hand, the rapid increase in the compressive strength has been seen with the variation of cement percentage. Increase the strength continues in phase 2 with the variation of cement along with coarse sand. At $20 \%$ cement combination gives the maximum strength 
at (20 TFASDRT) were found (9.01 MPa). Figure 7(c) shows the variation in compressive strength for phase 2 observation.

\subsection{Seepage Characteristics of Fly Ash Based Composite Material}

It had already been observed, how the soil type can make such differences to the value of permeability. e.g., clean gravel has a k value greater than $10^{\circ} \mathrm{cm} / \mathrm{s}$, sand between $10^{\circ}$ and $10^{-3} \mathrm{~cm} / \mathrm{s}$, silt between $10^{-3}$ and $10^{-6}$ $\mathrm{cm} / \mathrm{s}$ and clay has $\mathrm{k}$ values smaller than $10^{-6} \mathrm{~cm} / \mathrm{s}$. The variation in the value of permeability is very large that we are interested mostly in determining the power to which 10 must be raised while expressing the permeability value [11]. Using experimental data [12] as summarized in Table 5 were determined the permeability of composite material on the same ratios using in the present study in which F.A as a main constituent and other materials are subsidiary. As it can be seen in Figure 7(d) and Figure 7(e) the permeability (k) decreases from $4.603 \times$ $10^{-7}$ to $0.874 \times 10^{-7} \mathrm{~m} / \mathrm{s}$. The experimental study reveals that the lower permeability values were obtained when increasing the percentage of $\mathrm{C}$ at fixed percentage of T.F.A and R.S.D. whereby $\mathrm{k}$ dropped sharply with variation of C.S with C. The permeability (k) falling in the range of $10^{-7}$ which is much closer to the value of clay which is available in the market for making bricks and roof tiles.

\subsection{Comparison of Past Experimental Result}

Only few studies have been conducted on fly ash based bricks and tiles. Since fly ash based bricks and tiles is an assemblage of fly ash and other materials. It is generally believed that the strength and durability of fly ash based bricks and tiles would lie somewhere between that of bond of fly ash and other mixed materials. It may be true in cases when one combination of mould, i.e., cement, fly ash, sand and stone dust, etc is substantially weaker and softer than other, for example variation of these materials play a significant role to change their strength as reported by [13], conducted series of tests on different combination with partial replacement of clay for making fly ash bricks. It was observed that the combination of materials play a significant role to change the compressive strength. The combination of fibre reinforced fly ash lime stone dust brick (10FRFALSDB3') was found to have highest compressive strength $(9.155 \mathrm{MPa})$ with $10 \%$ stone dust and sand combination at $10 \%$ cement. It was found that when the amount of treated fly ash changes with respect to the stone dust and sand replacement, the compressive strength increased and was found to be maximum $25 \%$ stone dust-sand combination

Table 6. Comparison of past experimental results of fly ash based bricks and roof tiles.

\begin{tabular}{|c|c|c|c|c|c|c|}
\hline \multicolumn{3}{|c|}{ J. Alam et al. (2013) } & \multicolumn{4}{|c|}{ J.N Akhtar et al. (2010) } \\
\hline $\begin{array}{c}\text { Mould } \\
\text { Designation }\end{array}$ & $\begin{array}{c}\text { Compressive } \\
\text { Strength (MPa) }\end{array}$ & $\mathrm{K}_{27}(\mathrm{~m} / \mathrm{s})$ & $\begin{array}{c}\text { Mould } \\
\text { Designation }\end{array}$ & $\begin{array}{c}\text { Compressive } \\
\text { Strength (MPa) }\end{array}$ & $\begin{array}{c}\text { Mould } \\
\text { Designation }\end{array}$ & $\begin{array}{c}\text { Compressive } \\
\text { Strength }(\mathrm{MPa})\end{array}$ \\
\hline 00FABT & 3.636 & $18.45 \times 10^{-7}$ & 00FAB & 3.348 & 00FALSDB1 & 3.666 \\
\hline 05FABT & 3.688 & $17.60 \times 10^{-7}$ & 05FAB & 3.690 & 05FALSDB2 & 4.235 \\
\hline 10FABT & 3.755 & $16.00 \times 10^{-7}$ & $10 \mathrm{FAB}$ & 4.390 & 10FALSDB3 & 7.156 \\
\hline 15FABT & 3.940 & $14.70 \times 10^{-7}$ & $15 F A B$ & 5.385 & 15FALSDB4 & 6.569 \\
\hline 20FABT & 3.690 & $18.10 \times 10^{-7}$ & 20FAB & 4.450 & 20FALSDB5 & 4.790 \\
\hline 00TFABT & 4.055 & $14.65 \times 10^{-7}$ & 00FRFAB & 3.748 & 00FRFALSDB1' & 3.666 \\
\hline 05TFABT & 4.100 & $14.05 \times 10^{-7}$ & 05FRFAB & 3.990 & 05FRFALSDB2' & 4.235 \\
\hline 10TFABT & 4.310 & $13.85 \times 10^{-7}$ & 10FRFAB & 4.790 & 10FRFALSDB3' & 8.156 \\
\hline 15TFABT & 4.535 & $12.75 \times 10^{-7}$ & 15FRFAB & 6.350 & 15FRFALSDB4' & 6.569 \\
\hline 20TFABT & 4.315 & $12.95 \times 10^{-7}$ & 20FRFAB & 4.750 & 20FRFALSDB5' & 4.790 \\
\hline 00TFASDBT & 4.845 & $23.50 \times 10^{-7}$ & 00FALB & 3.685 & 10FALSDB6 & 8.160 \\
\hline 05TFASDBT & 5.300 & $22.50 \times 10^{-7}$ & 05FALB & 4.065 & 15FALSDB7 & 8.330 \\
\hline 10TFASDBT & 5.480 & $20.40 \times 10^{-7}$ & 10FALB & 4.865 & 20FALSDB8 & 8.520 \\
\hline 15TFASDBT & 5.900 & $17.80 \times 10^{-7}$ & 15FALB & 6.599 & 25FALSDB9 & 8.890 \\
\hline 20TFASDBT & 5.714 & $23.10 \times 10^{-7}$ & 20FALB & 4.596 & 30FALSDB10 & 7.480 \\
\hline 10TFASDBT & 4.690 & $23.30 \times 10^{-7}$ & 00FRFALB & 4.185 & 10FRFALSDB6' & 8.315 \\
\hline 15TFASDBT & 6.896 & $14.97 \times 10^{-7}$ & 05FRFLAB & 5.465 & 15FRFALSDB7' & 8.545 \\
\hline 20TFASDBT & 6.240 & $17.53 \times 10^{-7}$ & 10FRFALB & 5.850 & 20FRFALSDB8' & 8.625 \\
\hline 25TFASDBT & 5.770 & $20.75 \times 10^{-7}$ & 15FRFALB & 7.859 & 25FRFALSDB9' & 9.155 \\
\hline 30TFASDBT & 5.390 & $22.29 \times 10^{-7}$ & 20FRFALB & 5.460 & 30FRFALSDB10' & 7.755 \\
\hline
\end{tabular}



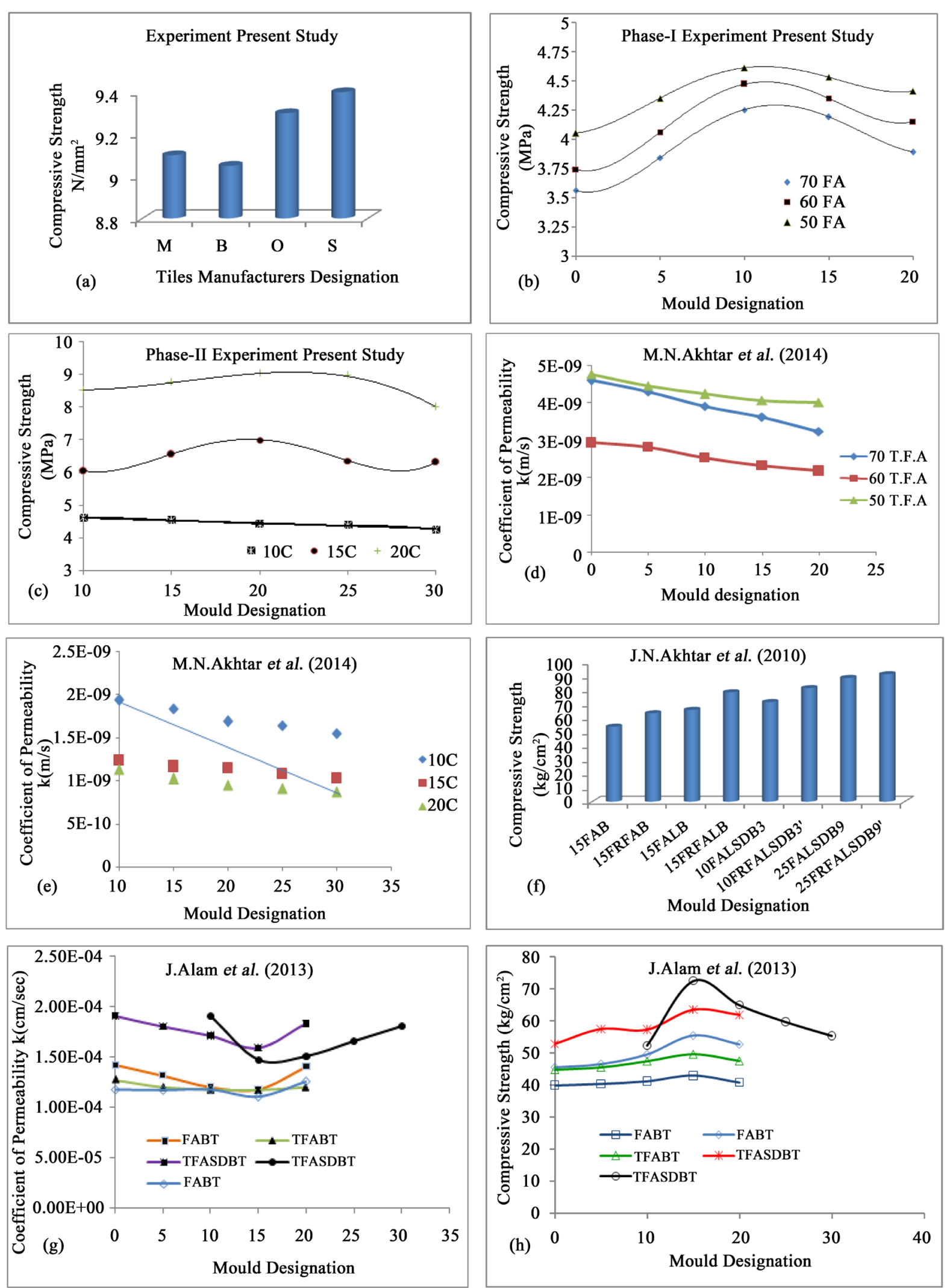

Figure 7. (a), (b), and (c), for present experimental work, and (d), (e), (f), (g), and (h) work of other researches with experimental curves obtained in several published studies. 
with 50\% treated fly ash. The variation of strength is shown in Figure 7(f). Based on experimental data [14] conducted a series of tests on fly ash based brick tiles. It was observed that the compressive strength of these tiles increases with increase in bond strength of the composite material along with other factors. It has been also observed that the permeability reached at lower value at the same whereas compressive strength was reached at maximum. After experimental investigation it has been carried out that the tiles were failed on lower compressive strength as compare to the conventional clay brick tiles. The highest compressive strength reached (6.896 $\mathrm{MPa}$ ) for the combination of 15TFASDBT. The detailed experimental data of the past investigations are given in Table 6. Figure 7(g) and Figure 7(h) shows the seepage and compressive strength behavior of the study.

\subsection{Moulds Ratio Fly Ash Mixed with Different Materials}

Six different combination grades of moulds (C: T.F.A: C.S: S.D) by volume were used in the study, viz., 1:7:1:1, 00TFASDRT (70\% TFA), 1:6:2:1 10TFASDRT, (60\% TFA) and 1:5:3:1, 10TFASDRT (50\% TFA) observed at highest compressive strength for the first phase of the observation. For phase second 1:5:2:2 20TFASDRT (10\% C), 1:3.33:1:1.33 20TFASDRT (15\% C), and 1:2.5:0.5:1 20TFASDRT (20\% C) achieved highest value of compressive strength. The compressive strength was obtained by averaging the data from three observations of each grade.

The failure modes of tested samples are shown in Figure 8. Weak mortar was found to be very weak and soft as compared to other three i.e., intermediate, strong and very strong. Intermediate mortar perform stable as compared to weak and strength increased about (29.41\%), then Strong mortar performed well in terms of strength and ductility as compared to other two, strong mortars was found (51.40\%), higher than intermediate mortar, in comparison of strong mortar very strong mortar was reached the highest strength about (29.08\%) more than the strong.

\subsection{Stress-Strain Curves Behavior}

Several tests were carried out in order to evaluate the uniaxial compressive stress-strain curves of fly ash and clay based tiles. The fly ash based tiles were constructed with different combination moulds. Local clay tiles from four different manufacturers (designated as $\mathrm{M}, \mathrm{B}, \mathrm{S}$, and $\mathrm{O}$ ) were used, having approximate length, width, and height as 230, 110, and $38 \mathrm{~mm}$ respectively. Clay and fly ash tiles were subjected to monotonically increasing displacement loading (strain controlled) at their top which was applied vertically by a $250 \mathrm{kN}$ load and \pm 125 mm displacement capacity MTS servo-hydraulic actuator. However, tiles units were tested in a $2000 \mathrm{kN}$ universal testing machine under stress-controlled loading. In the case of clay and fly ash tiles, the displacements were recorded on their faces as shown in Figure 8.
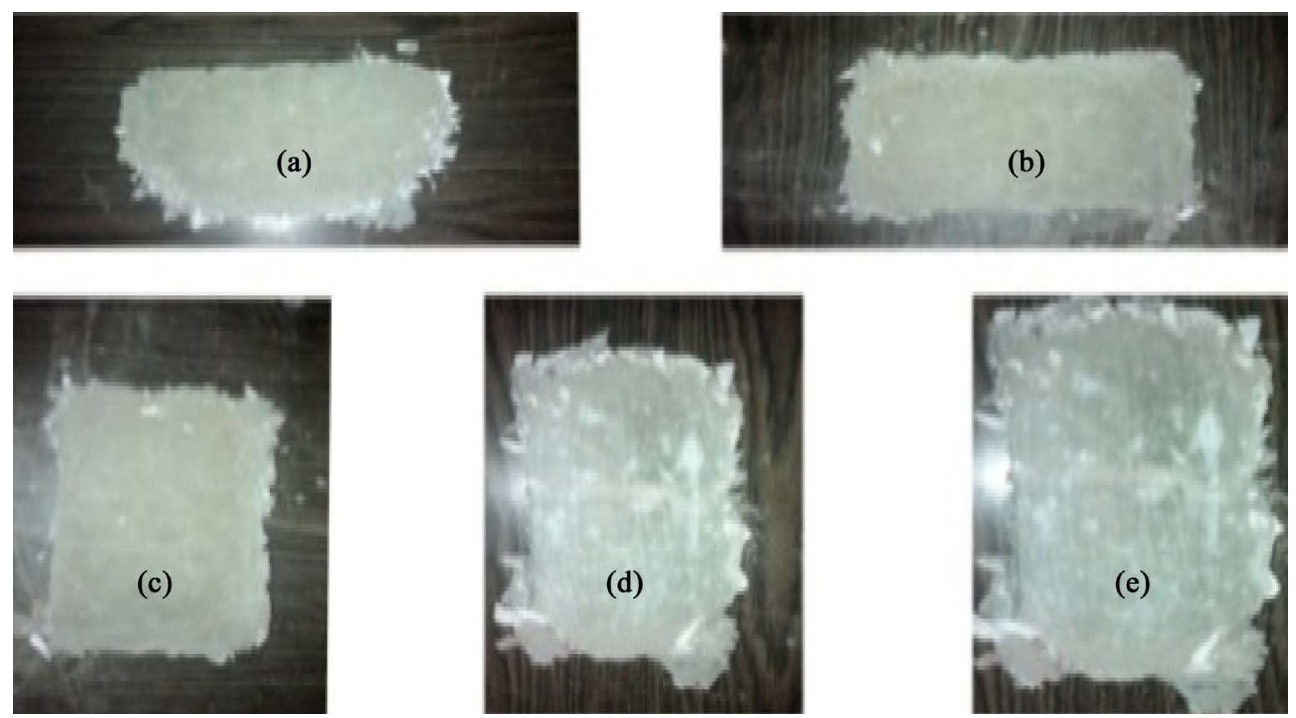

Figure 8. Typical failure modes of: (a) Weak, 00TFASDRT (70\% TFA), (b) intermediate, 10TFASDRT (60\% TFA), (c) intermediate, 10TFASDRT (50\% TFA), (d) strong, 20TFASDRT (15\% C), (e) very strong, 20TFASDRT (20\% C). 


\subsection{Stress-Strain Curves for Clay Tiles}

The tests were performed in accordance with [9], and [10]. The stress-strain curves for the four types of clay tiles obtained by averaging the stress strain data from ten samples of each type of clay tiles. The tiles were found to be behaving linearly up to about one-third of the ultimate failure load after that the behavior became highly nonlinear. An average stress-strain curve for all the tiles types used in the study is also shown in Figure 9. The summary of results including water absorption is given in Table 4. For different tiles used in the study, mean compressive strength were found (9.2 MPa).

\subsection{Stress-Strain Curves for Fly Ash Tiles}

The stress-strain curves for six grades of mould obtained by averaging the data from ten specimens of each grade. Initial straight portion of the stress-strain curve (up to about one-third of mould strength) is followed by a nonlinear curve almost same as stress-strain curves for standard clay brick tiles discussed above which extends well beyond the strain limits corresponding to the tiles samples. Strain readings on the falling branch of the stress-strain curve could not be recorded for the very weak moulds because of its brittle and explosive crushing failure after reaching the ultimate strength. The crushing failure of other grade specimens was more ductile and nonexplosive. The summary of test results of six grades for Phase 1 and phase 2 are given in Table 5. The majority of tiles used in the phase 2 observation were stronger and stiffer than phase 1. Figure 10(a) shows that the

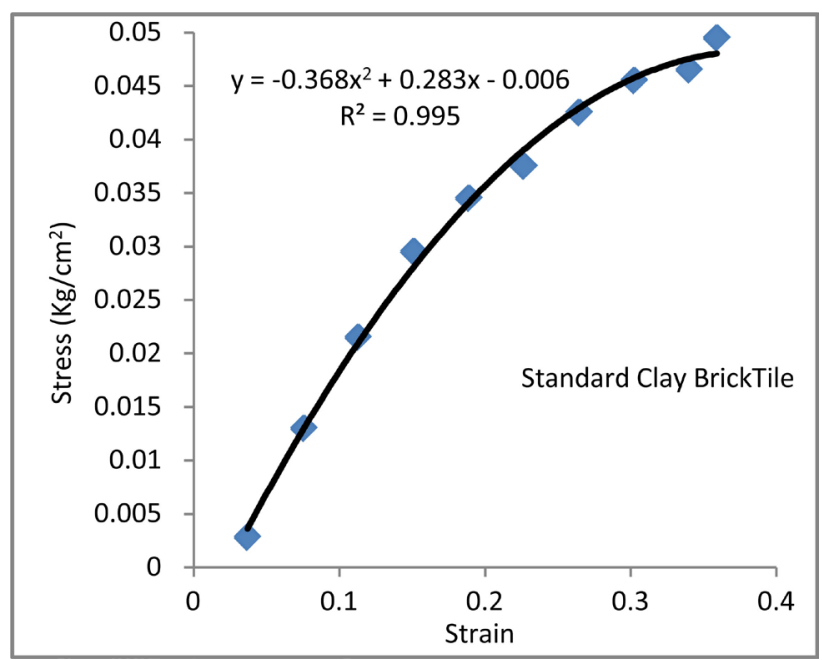

Figure 9. Stress-strain curve behavior for standard clay brick tiles.
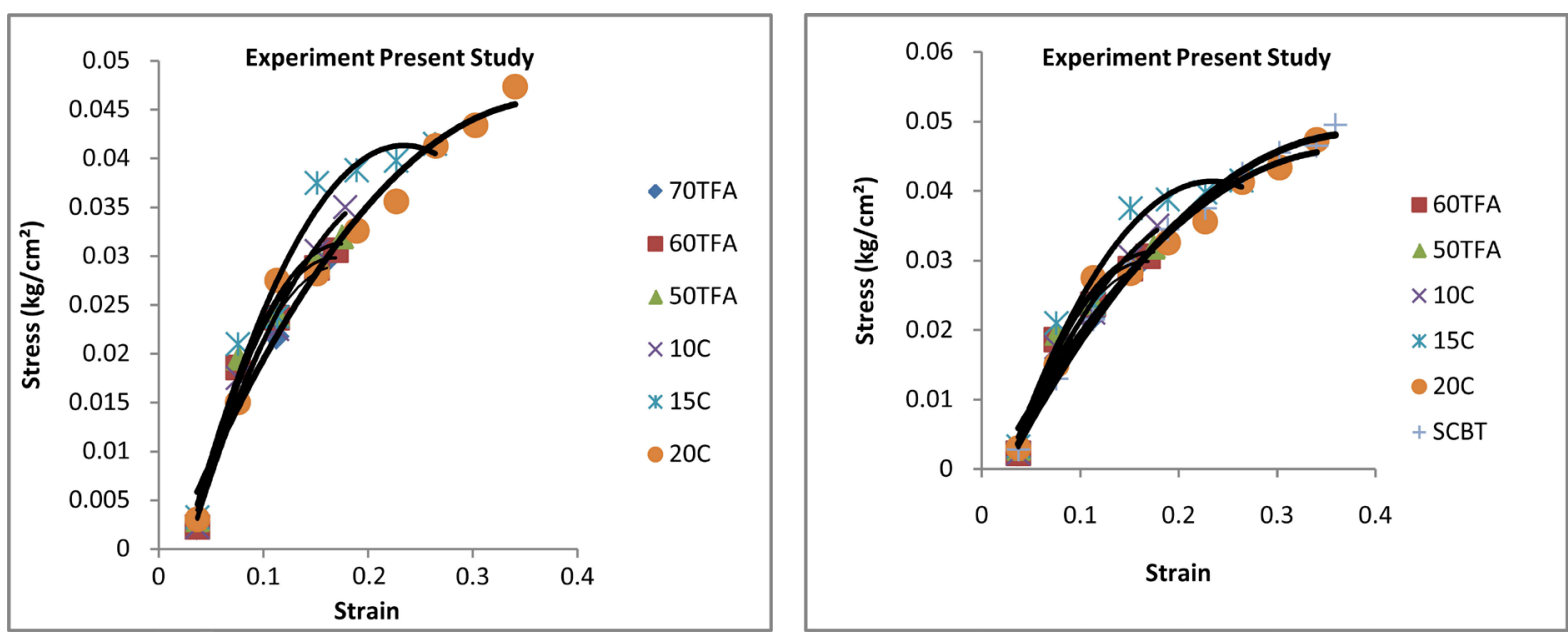

Figure 10. (a) Stress-strain curve behavior of TFASDRT, (b) comparison of stress-strain curves of TFASDRT and SCBT. 
stress-strain curve comparison for six different combination grades of moulds TFASDRT. Data points represent experimental results and solid lines represent corresponding trend lines. A comparison of stress-stain curves generated by the TFASDRT and SCBT obtained in the present experimental study is shown in Figure 10(b), which show a very close match between the TFASDRT and SCBT curves.

\section{Summary of Test Results}

Weak mortar falls in between those tiles and mortar. On the other hand, for tiles constructed with intermediate and strong mortar the stress-strain curves of tiles fall on lower side and the pattern of the curves about to same as standard clay tiles curve. The final combination of which is designated by very strong mould as shown in Figure 10(a), the stress-strain curves pattern almost same as a standard clay tiles curve (Refer Figure 9). Thus, there is a significant improvement in the ductility of tiles in compression without any considerable compromise with the compressive strength because of using treated fly ash (TFA) combination in the present study after addition of optimum percentage of lime with one percent of W.P.F. The equation of the each mould, $\mathrm{R}^{2}$ and $\sigma$ is the standard error of estimate reported in Table 7. $\mathrm{R}^{2}$ is the coefficient of determination between the experimentally obtained values and values obtained by regression analysis. A value of $\mathrm{R}^{2}$ close to unity indicates a good fit and that close to zero indicates a poor fit, whereas it is desirable that $\sigma$ is a minimum, implying that the scatter in the data about the estimated value is a minimum.

\section{Control Point Defining the Characteristics of the Study}

Based on the present and past studies five control points were indentified, which correspond to the experimentally observed data and representing compressive stresses behavior, stress-strain characteristics and their interrelationship on the present study.

The control points identified during the tests are as follows:

1) The compressive strength has been increased by $30.65 \%$ compared to the past study carried out by [14].

2) Addition of W.P.F provides more strength and ductility in the tiles as compared to the other past studies refer (Figure 8 Typical failure modes).

3) The present study, represents the stress-strain curves, remain linear up to 0.33 compressive prism strength of the tiles. Thereafter, several cracks were starting in tiles introducing nonlinearity in the samples.

4) At 0.75 compressive prisms strength is where vertical splitting cracks in tiles start developing at about this stress.

5) Stress-strain curves have been generated by present experimental data and compared with the experimental curve obtained by standard clay brick tile is fall almost on same the pattern.

\section{Conclusion}

This study demonstrates the composite effect of waste materials along with different percentage of cement. The objective of research was to investigate experimentally the compressive behavior of fly ash tiles and to develop the stress-strain curves. The relationship between different combinations of materials, mix mortars and sample relations is suggested that the composite material is fit to develop the full required strength. Tiles mould compressive strength was found to increase with an increment in percentage of cement. However, the increase of compressive strength also depends on T.F.A, C.S and R.S.D combinations. Stress-stain curves of these tiles with

Table 7. Summary of test result for clay and fly ash based tiles.

\begin{tabular}{|c|c|c|c|c|c|}
\hline \multicolumn{3}{|c|}{ Designations Independent Dependent } & \multirow{2}{*}{ Equation of Curves } & \multirow{2}{*}{$\mathrm{R}^{2}$} & \multirow{2}{*}{$\sigma$} \\
\hline & Variable, $y$ & Variable, $x$ & & & \\
\hline 70TFA & Stress & Strain & $y=-1.411 x^{2}+0.487 x-0.013$ & 0.973 & 0.25 \\
\hline 60TFA & Stress & Strain & $y=-1.572 x^{2}+0.527 x-0.014$ & 0.984 & 0.25 \\
\hline 50TFA & Stress & Strain & $y=-1.423 x^{2}+0.499 x-0.012$ & 0.979 & 0.19 \\
\hline $10 \mathrm{C}$ & Stress & Strain & $y=-0.842 x^{2}+0.402 x-0.010$ & 0.984 & 0.12 \\
\hline $15 \mathrm{C}$ & Stress & Strain & $y=-0.946 x^{2}+0.443 x-0.010$ & 0.968 & 0.31 \\
\hline $20 \mathrm{C}$ & Stress & Strain & $y=-0.351 x^{2}+0.263 x-0.003$ & 0.967 & 0.37 \\
\hline
\end{tabular}


fly ash and other combination were observed and recline slightly below the stress-strain curves of standard clay tiles. Therefore, more experimental study is required with different combination of these tiles grades to develop a generalized model for compressive behavior of tiles. The fly ash mixed with W.P.F is supportive in enhancing the strength of tiles mortar and it does not allow water to seep in, as it is water proof, furthermore their use, helps in reducing environmental pollution and saving energy. The results showed that the W.P.F reinforcement improved the peak and ultimate strength of tiles and somewhat reduced the fragility of the cemented sand. In addition, the initial stiffness was not significantly changed by the inclusion of fibers and the consumption of W.P.F reduced the destructive and adverse effects of polythene that they blocked the drains and it was not mixed with the soil. The safe utilization of these two waste materials is very essential for the protection of our environment. By the utilization of fly ash for making roof tiles in an equal volume of top soil, which will otherwise be used for making clay, tiles can be saved.

\section{Acknowledgements}

The writers gratefully acknowledge the help extended by Dr. Urfi, PhD in chemistry A.M.U Aligarh India in the analysis of chemical properties of waste materials, and also acknowledge the help of the staff at the structural engineering laboratory at A.M.U Aligarh, India, in conducting the experiments.

\section{References}

[1] ASTM (2005) American Standards for Testing and Materials. Standard C618-05 "Standard Specification for Coal Fly Ash and Raw or Calcined Natural Pozzolan for Use in Concrete”.

[2] ASTM (2006) American Standards for Testing and Materials. Standard C593-06 "Standard Specification for Fly Ash and Other Pozzolans for Use with Lime for Soil Stabilization”.

[3] Xu, L.L., Guo, W., Wang, T. and Yang, N.R. (2005) Study on Fired Bricks with Replacing Clay by Fly Ash in High Volume Ratio. Construction and Building Materials, 19, 243-247. http://dx.doi.org/10.1016/j.conbuildmat.2004.05.017

[4] Demir, I., et al. (2005) Utilization of Kraft Pulp Production Residues in Clay Brick Production. Building and Environment, 40, 1533-1537. http://dx.doi.org/10.1016/j.buildenv.2004.11.021

[5] Browne, R.D. and Bamforth, P.B. (1977) Tests to Establish Concrete 15585 Pumpability. ACI Structural Journal, 74, 193-203.

[6] I.S: 3812 (1983) Specification for Fly Ash as Pozollana and Admixture (First Revision).

[7] I.S: 8112 1989) 43 Grade Ordinary Portland Cement Specifications (First Revision).

[8] I.S. 2720-7 Methods of Test for Soil Part 7 Determination of Water content-Dry Density Relation Using Light Compaction (Second Revision). 1983.

[9] ASTM (2001) Standard Test Methods for Sampling and Testing Brick and Structural Clay Tile. Masonry Test Methods and Specifications for the Building Industry, ASTM-C67-00, 4th Edition, Philadelphia.

[10] Indian Standards (IS.1992a) Indian Standard Methods of Test of Burn Clay Building Bricks_-Part 1: Determination of Compressive Strength, IS 3495, 3rd Rev., Bureau of Indian Standards, New Delhi.

[11] Ranjan, G. and Rao, A.S.R. (2000) Basic and Applied Soil Mechanics. 2nd Edition, New Age International (P) Limited, Publishers, Darya Ganj.

[12] Akhtar, M.N., et al. (2014) Use of the Falling-Head Method to Assess Permeability of Fly Ash Based Roof Tiles with Waste Polythene Fibre. International Journal of Scientific \& Engineering Research, 5, 476-483.

[13] Akhtar, J.N., et al. (2010) An Experimental Study on Fibre-Reinforced Fly Ash Based Lime Bricks. International Journal of physical Sciences, 5, 1688-1695.

[14] Alam, J., et al. (2013) Flay Ash Based Brick Tiles: An Experimental Study. International Journal of Emerging Trends in Engineering and Development, 6, 2249-6149. 


\section{Notation}

The following symbols are used in this paper:

$\mathrm{C}=$ Cement;

C.S = Coarse Sand;

FA = Fly ash;

IRA = Initial Rate of Absorption;

$\mathrm{K}=$ Permeability;

$\mathrm{kN}=$ Kilonewton;

OMC = Optimum Moisture Contents;

R.S.D = Radish Stone Dust;

SCBT $=$ Standard Clay Brick Tile;

TFA = Treated Fly Ash;

TFRT = Fly Ash Roof Tiles;

TFASDRT $=$ Treated Fly Ash Stone Dust Roof Tile;

WA = Water Absorption;

W.P.F $=$ Waste Polythene Fibre. 